\title{
Factors Influencing Utilization of Health Services in Kenya: The Case of Homa Bay County
}

\author{
Otieno Stephen Odiwuor ${ }^{1}$, Macharia David ${ }^{2}$ \\ ${ }^{1}$ Agency for Cooperation and Research in Development (ACORD), Nairobi, Kenya \\ ${ }^{2}$ Department of Distance Studies, University of Nairobi, Kenya
}

\section{Article Info \\ Article history: \\ Received Sept 8, 2014 \\ Revised Oct 20, 2014 \\ Accepted Nov 15, 2014}

\section{Keyword:}

Accessibility

Equity

Health financing

Quality

Service delivery

\begin{abstract}
In order to improve efficiency in health service delivery in Kenya, the Ministry of Health has developed structures through inter-sectoral collaboration at various levels. Despite efforts by the government and key stakeholders to improve health sector, utilization of health services still remains a major challenge. The purpose of the study was to investigate factors that influence utilization of health services in Homa Bay County, Kenya. The study employed survey design and focused on health beneficiaries, District Health Management Team and other key health stakeholders, and used both quantitative and qualitative data. Quantitative data was collected through household interviews of 384 respondents and qualitative data was generated through Key Informant Interviews of 16 respondents. The study reveals that health financing, service delivery, quality, accessibility and equity influence utilization of health services in Homa Bay County. It is for these reasons that the study recommends that the government should allocate adequate budget towards health services, avail adequate trained health workers, and improve infrastructure in health facilities as well as drugs and other supplies. There is also need for further research on cultural factors influencing utilization of health services.
\end{abstract}

Copyright (C) 2014 Institute of Advanced Engineering and Science. All rights reserved.

\section{Corresponding Author:}

Stephen Otieno,

Agency for Cooperation and Research in Development (ACORD),

P.O. Box 13988 - 00400 Nairobi - Kenya.

Email: Smakotieno@yahoo.com

\section{INTRODUCTION}

In 1994, the Government of Kenya (GOK) approved the Kenya Health Policy Framework (KHPF) as a blueprint for developing and managing health services. It spells out the long-term strategic imperatives and the agenda for Kenya's health sector. To operationalise the Framework, the Ministry of Health (MOH) developed the Kenya Health Policy Framework Implementation Action Plan and established the Health Sector Reform Secretariat (HSRS) in 1996 under a Ministerial Reform Committee (MRC) in 1997 to spearhead and oversee the implementation process. A rationalization programme within the $\mathrm{MOH}$ was also initiated. The above policy initiatives aimed at responding to the following constraints: decline in health sector expenditure, inefficient utilization of resources, centralized decision making, inequitable management information systems, outdated health laws, inadequate management skills at the district level, worsening poverty levels, increasing burden of disease, and rapid population growth [1].

The challenge facing the government is to reverse these constraints. The National Health Sector Strategic Plan II (2005-2010) proposes to improve service delivery by using six levels of care delivery: Level 1 , the community level; Levels 2 and 3 (dispensaries, health centres, and maternity/nursing homes); and Levels 4-6 (primary, secondary and tertiary hospitals). In this way, the existing vertical programmes will come together to provide services to the age groups at these various levels. The plan adopts a broader 
approach - a move from the emphasis on disease burden to the promotion of individual health based on the various stages of the human cycle: pregnancy and the newborn (up to two weeks of age); early childhood (two weeks to five years); late childhood (6-12 years); youth and adolescence (13-24 years); adulthood (2559); and the elderly (60+ years).

The health sector comprises the public system, with major players including the $\mathrm{MOH}$ and parastatal organizations, and the private sector, which includes private for-profit, NGO, and FBO facilities. According to the most recent health management information system (HMIS) data, there are over 5,000 health facilities across the country operated by three owner systems, with the government running $41 \%$ of the facilities, nongovernmental organizations (NGOs) 15\%, and private businesses 43\% (MOH, 2007). The government owns most of the hospitals, health centers, and dispensaries, while clinics and nursing homes are entirely in the hands of the private sector. According to Ministry of Medical Services (MOMS) records, there are 165 health facilities spread across the three districts forming Homa Bay County; Homa Bay, Rachuonyo and Suba Districts.

The public health system consists of the following levels of health facilities: national referral hospitals, provincial general hospitals, district hospitals, health centres, and dispensaries. National referral hospitals are at the apex of the health care system, providing sophisticated diagnostic, therapeutic, and rehabilitative services. The two national referral hospitals are Kenyatta National Hospital in Nairobi and Moi Referral and Teaching Hospital in Eldoret. The equivalent private referral hospitals are Nairobi Hospital and Aga Khan Hospital in Nairobi. Provincial hospitals act as referral hospitals to their district hospitals. They also provide very specialized care. The provincial level acts as an intermediary between the national central level and the districts. They oversee the implementation of health policy at the district level, maintain quality standards, and coordinate and control all district health activities. Similar private hospitals at the provincial level include Aga Khan Hospitals in Kisumu and Mombasa. New Nyanza Provincial General Hospital is the referral hospital for Homa Bay County.

As a result of health sector reforms that have decentralized health services, services are integrated as one goes down the hierarchy of health structure from the national level to the provincial and district levels. Under decentralisation, the district handles supervisory responsibilities. Unfortunately, supervision has not been very effective, as one technical person is often required to supervise several technical areas of service delivery at lower levels. The Provincial Health Management Team (PHMT) provides supervision and management support to the districts and sub-districts within the province. At the district level, curative services are provided by district hospitals and mission hospitals. Public health services are managed by the District Health Management Team (DHMT) and Public Health Unit of the district hospitals. The DHMT and District Health Management Board (DHMB) provide management and supervision support to rural health facilities (sub-district hospitals, health centres, and dispensaries). At the sub-district level, both preventive and curative services are provided by the health centres as well as dispensaries and outreach services to the communities within the catchment areas. Basic preventive and curative services for minor ailments are being addressed at the community and household level with the introduction of the community package [1].

Although several health-oriented NGOs operate throughout the country, the population covered by these NGO health services cannot be easily determined. The $\mathrm{MOH}$ and external donors support the health services offered by NGOs and the private sector in several ways. Depending on their comparative advantage, NGOs, FBOs, and community-based organisations (CBOs) undertake specific health services. The $\mathrm{MOH}$ provides support to mission health facilities by training their staff as well as seconding staff to these facilities and offering drugs and vaccines.

Currently, the private sector (both for-profit and not-for-profit) contributes over 40 percent of health services in the country, providing mainly curative health services and very few preventive services. Modalities exist for $\mathrm{MOH}$ supervision and monitoring of NGO, FBO and other private-sector facilities. The NGOs and private facilities work with communities in collaboration with the DHMT. The community programmes report to the DHMBs, which reports to the headquarters through the Provincial Health Management Boards. Their activities are guided by $\mathrm{MOH}$ standards and protocols.

While there are efforts by the government and other stakeholders to improve provision of health services in Kenya, there are major gaps in relation to utilization of healthcare services especially at community level. Various studies have been conducted to assess factors that influence utilization of health services internationally and even in Kenya and some of the factors include; cost of health services and quality of services.

The current literature acknowledges that there are multiple determinants of health, which recognize the role of biology, behaviour, culture, economics, psychological, environmental and social factors and the interconnectedness of these [2]-[5]. In developing countries, these factors are newer considerations as countries with limited resources struggle to cope with mortality and morbidity as a result of communicable disease, injury, poverty, sexual and reproductive health issues, and more recent concerns such as 
hypertension, heart disease [6] and diabetes that are more lifestyle-oriented results of development [7]. However, more recent studies are beginning to discover that unless health and ill-health in less developed countries is considered in this broader context, inequalities will only become more evident [8]. Therefore, knowledge of the patterns that influence the use of health and medical services in developing countries are needed to address this.

Studies conducted in Kenya and other developing countries reveal the following factors as influencing utilization of health services: cost/financing, access, health delivery, attitude, traditional health services, low education level, awareness of health services, quality of health services, and equity in healthcare provision. According to a study conducted by Dustin, the two biggest factors currently preventing healthcare from reaching a larger proportion of the population are the high cost of services, and poor access to health facilities [9].

While studies have been done on utilization in some regions in Kenya and other countries, including the 2003 Kenya Household Health Expenditure and Utilization Survey, no study have been done in Homa Bay County, comprising the three districts; Rachuonyo, Homa Bay and Suba. The purpose of this study was to investigate factors that influence utilization of health services in Homa Bay County, Kenya. The study was guided by the following five objectives:

i. To establish the influence of health financing on utilization of health services in Homa Bay County

ii. To assess the influence of service delivery on utilization of health services in Homa Bay County

iii. To establish the influence of quality health services on utilization of health services in Homa Bay County

iv. To assess influence of accessibility to healthcare services on utilization of health services in Homa Bay Country

v. To establish influence of equity in healthcare provision on utilization of health services in Homa Bay County

The study was justified by high poverty levels of $68 \%$ (average) across the three districts forming Homa Bay County coupled with inadequate health infrastructure and other factors influence utilization of health services in this county. Additionally, health being an important aspect of livelihood, it is important to assess the level of utilization of such services depending on the prevailing circumstances. The study was necessary for Homa Bay County being in Nyanza Province, where health service provision and utilization remains a major concern.

In order to improve provision of health services in Kenya, the National Health Sector Strategic Plan II (2005-2010) proposes to improve service delivery by using six levels of care delivery. Homa Bay County has 165 health facilities across levels 1 to 4, providing health services to the people but various factors limit utilization of such services in the county. This study has generated evidence on some of the key factors that influence utilization of health services in order to inform policy makers, Ministry of Health - both at county and central government levels - to effectively respond to health systems in the county. The study would benefit the local community by identifying key factors influencing utilization of health services and suggesting how to improve the situation. The study would also benefit researchers by providing evidence for reference regarding utilization of health services in many places including Homa Bay County.

The study was conducted across the three districts; Homa Bay, Rachuonyo and Suba, forming Homa Bay County and it targeted local community who are the health beneficiaries, public and private health facilities and key health stakeholders, especially health NGO representatives in the county. In carrying out this study, two assumptions were taken into consideration; that the respondents would agree to participate in the survey, and that they would be truthful - providing accurate information useful for the study. Based on this report, the expected respondents participated in the study and the findings are in line with other relevant studies that have been done elsewhere within the country and outside, which implies that most of the respondents were truthful.

\section{RESEARCH METHOD}

This was a cross-sectional descriptive and participatory study involving both quantitative and qualitative methodologies. The study was conducted in two phases. Phase1: Review of relevant literature to inform the indicators and variables influencing utilization of health services globally, in the continent as well as Kenya and gaps that exist in Homa Bay County to be considered during the implementation study. Phase2: Field visit to conduct face to face interviews in quantitative and qualitative methods using structured and semi-structured questionnaires and guides for data collection. The quantitative information answers the concerns of how much and what is the situation while the qualitative data answer the perception and feeling of the community and informants on the gaps that exist as far as utilization of health services in Homa Bay County is concerned. 
The study employed survey research design and it involved interviewing the local community members who are the recipients of health services, health workers and professionals as well as other key stakeholders. The study population included households in the county, District Health Management Team (DHMT) members, and NGOs representatives. The total household population of Homa Bay County is 206,255 according to the 2009 Kenya Population and Housing Census. This household population is distributed across the three districts as follows: Homa Bay $(79,540)$, Rachuonyo $(81,395)$ and Suba $(45,320)$. In addition to the households, there are 21 DHMT members from the three districts forming Homa Bay County as well as 23 health NGOs. Based on the categories of respondents for the study, a sample of 400 was drawn across the various categories. The sample was proportionate to the population. Table 1 outlines the breakdown of study respondents.

Table 1. Breakdown of study respondents

\begin{tabular}{ccccc}
\hline Category & Sub category & \multirow{2}{*}{ Total Population } & \multicolumn{2}{c}{ Sample } \\
\cline { 3 - 5 } & Household interviewees & 206,255 households & Percentage & Sample size \\
\hline Community & DHMT & 21 & $43 \%$ & 384 \\
Key Informants & NGOs/CBO representatives & 23 & $30 \%$ & 7 \\
Health & Total & & & \\
NGOs/CBOs & & & \\
\hline
\end{tabular}

To effectively get accurate and representative data, two broad data collection methods were used; that is, secondary and primary data collection. Secondary data collection was done through desk review and discussion with key stakeholders while primary data collection was done through individual household interviews and key informant interviews with health workers and other key stakeholders. The first level of validation involved review of key variables with the guidance of my supervisor. This was followed by defense in which a team of panelists provided further guidance. In order to ensure reliability, rehearsals were done with the assistant(s) to ensure that they fully understood the instruments and were motivated enough to carry out the work without introducing any auxiliary questions which may distort the responses. The prepared interview guides were pre-tested with some of the target population before full administration to the selected sample.

The data captured constituted both quantitative and qualitative data. Quantitative data were analyzed using SPSS 17.0 by running frequencies, cross-tabulations, chi square tests, correlation and regression to generate various relationships, frequencies and comparisons. Qualitative data were transcribed and summarized along themes and sub themes to back up quantitative data.

\section{RESULTS AND ANALYSIS}

The study was conducted through individual interviews of 384 (179 males and 205 females), key informant interviews with nine DMHT representatives and seven NGOs representatives. This part of the report focuses on data analysis, presentation and interpretation based on the data collected from individual interviews and key informant interviews. It provides overview of factors influencing utilization of health services in Homa Bay County. The sub sections are based on the five independent variables that were studied.

\subsection{Health Financing}

Kenya is a low-income country with a severely limited health budget [10]. Access to good health services is poor especially in rural areas. In the late 1970s Kenya expanded its rural health facilities to meet the needs of its predominantly rural poor population adopting the 1978 Alma Ata Declaration on Primary health care [11]. In the 1990s Kenya followed the shift in health policy towards institutional and structural reform and market orientation of health services based on the 1993 World Development Report [12].

The ability to pay for health services determines whether people visit health facilities or not. The study revealed that among those who had visited health facilities to access health services, $49 \%$ had been to government health facilities, 35\% had been to NGO/FBO managed health facilities while 16\% had been to private health facilities within the county. This implies that majority get health services from public/government health facilities. This information appears in Figure 1. 


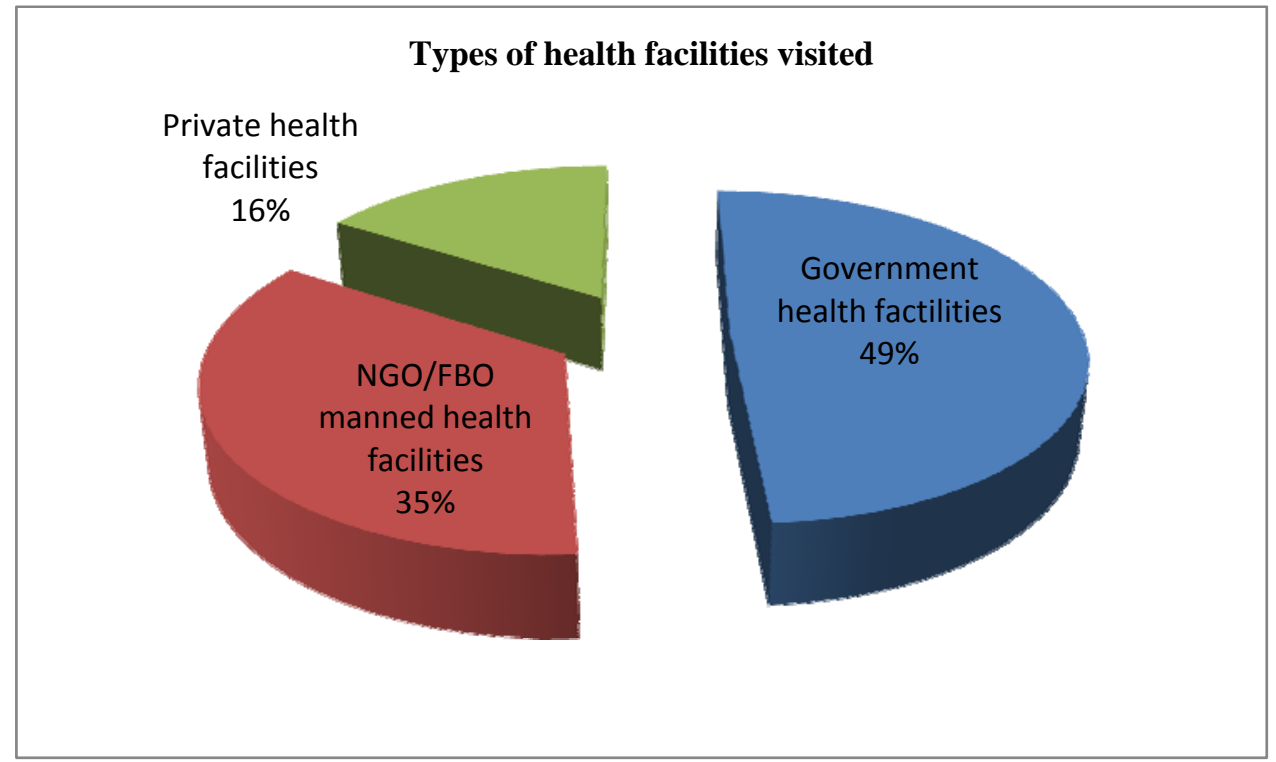

Figure 1. Types of health facilities visited

Payment for health services varies according to categories of health facilities. A cross tabulation of those who visited various health facilities and paid money is represented in Table 2. Among 189 respondents who visited public health facilities, 172 paid money while 17 did not. Among 135 who visited NGO/FBO manned health facilities, 103 paid while 32 did not. In addition, mong the 60 respondents who visited private health facilities, 57 paid while 3 did not. Looking across the three categories of health facilities visited, the study revealed that $86 \%$ paid for health services while $14 \%$ did not.

Table 2. Cross tabulation of type of health facility visited and payment of money

\begin{tabular}{|c|c|c|c|c|}
\hline & & \multicolumn{2}{|c|}{ Paid for services } & \multirow[b]{2}{*}{ Total } \\
\hline & & Yes & No & \\
\hline \multirow[t]{3}{*}{ Type facility visited } & $\begin{array}{l}\text { Government hospital (Health Centre, } \\
\text { Dispensary, Hospital) }\end{array}$ & $172(91 \%)$ & $17(9 \%)$ & $189(100 \%)$ \\
\hline & NGO/FBO manned health facility & $103(76 \%)$ & $32(24 \%)$ & $135(100 \%)$ \\
\hline & Private & $57(95 \%)$ & $3(5 \%)$ & $60(100 \%)$ \\
\hline Total & & 332 (86\%) & 52 (14\%) & 384 (100\%) \\
\hline
\end{tabular}

Health financing/funding is mainly from public funds that include allocation to the Ministry of Health, Constituency Development Fund (CDF), and Local Authority Transfer Fund (LATF). Other stakeholders in the health sector include NGOs contributions, private individuals and also cost sharing, The government of Kenya has always indicated the commitment to support health needs of her people and in this regard, is a signatory to Abuja Declaration which requires government to allocate at least $15 \%$ of national budget to health services. This, however, has not been accomplished as can be evident from 2010/2011 national budget where the government allocated 6.5\% of the budget to health while in 2011/2012 the allocation towards health is $5.5 \%$.

Focusing on Homa Bay County, Homa Bay district has allocated US\$ 48000; Rachuonyo District has allocated US\$ 109150 while Suba District has allocated US\$ 217966 towards health services (AOP 7). This allocation comprises GoK budget, CDF and LATF. Discussions with DHMT representative revealed that learning from previous budgets, this allocation cannot adequately support health requirements in the County. This implies that the deficit will have to be raised from cost-sharing, that is, to be paid by patients whenever they visit the health facilities.

According to a study by Hjortsberg on income as a determinant of health seeking behavior in Zambia [13], financial resources in terms of income were found to be better correlated with health, particularly in rural populations. One consideration for those that are self-employed in farming or small 
business from fish trade, for example, is that income can be unpredictable in terms of amount and regularity and this can be problematic in using health care. Onwujekwe and Uzochukwu in a study in Southeast Nigeria found that rural populations were less likely to pay the cost of health care treatment upfront and more likely to pay in installments [14]. The assumption in the Nigerian study therefore was that regularity of income may be a more appropriate predictor, for these particular survey populations, of not just willingness to pay for health care services, but ability to do so. This is also the case for Homa Bay County in Kenya where most people live below poverty line.

From the findings, most people are not able to pay for adequate health services due to low income and this corroborates the findings of a study conducted in Madagascar by Glick [15]. The Kenyan situation may even be worse considering the high cost of living which forces people to spend the little they have on food rather than spending on treatment. The linkages of health to poverty reduction and to long-term economic growth are powerful, much stronger than is generally understood. Poverty has adverse effects on health status; conversely, poor health contributes to being poor. This scenario implies that most people are not able to access health services due to inability to pay for such services considering high level of poverty in the County.

\subsection{Health Service Delivery}

Effective health service delivery is determined by the existence of health facilities, staffing and availability of drugs and other equipment/supplies. The study assessed health service delivery in terms of health facilities, staffing and availability of other equipment that facilitate delivery of health services. While in Homa Bay, there were health facilities providing various health services to the people, it was revelaed that such facilities have inadequate staffing of health workers and some of the health workers do not have adequate skills. As elsewhere in the country, district hospitals in the County concentrate on the delivery of health care services and generate their own expenditure plans and budget requirements based on guidelines from headquarters through the province. And as revelaed in 3.1, the government health service is supplemented by other stakeholders who together provide between 30 and 40 percent of the hospital beds in Kenya. As shown in Table 3, there are 165 health facilities of various types spread across the three districts making Homa Bay County.

Table 3. Health facilities in Homa Bay County

\begin{tabular}{|c|c|c|c|}
\hline \multirow{2}{*}{ Indicator } & \multicolumn{3}{|c|}{ District } \\
\hline & Homa Bay & Rachuonyo & Suba \\
\hline Hospitals & 3 & 4 & 4 \\
\hline Health centres & 9 & 13 & 15 \\
\hline Dispensaries & 34 & 34 & 25 \\
\hline Medical Clinics & 5 & 6 & \\
\hline Nursing Homes & 2 & 3 & \\
\hline VCT centres & & 5 & 2 \\
\hline Other & & 1 & \\
\hline Total & 53 & 66 & 46 \\
\hline & & 165 & \\
\hline
\end{tabular}

Source: MoMS, 2011; District Strategic Plans 2005-2010

The study revealed that while Homa Bay County has a considerable number of health facilities to address health needs of the people, health service delivery is hindered by shortage of adequately trained health workers and also inadequate essential equipment and supplies., For instance, in Homa Bay district there were 11 health facilities without all tracer drugs for more than two weeks (AOP 7). This implies that those who were sick during the period of the study could notreceive required services and this, in the long run, influences utilization of health services in Homa Bay County. This determinant is concerned with which type of health facility is more available to prospective users. This would include the level of expertise and treatment that could be assumed from the type of facility, that is a hospital versus a dispensary, or if public facilities are limited and not accessible, so private facilities have filled the gap, as is the case in Vietnam [16], [17], or Uganda [18],[19], or India [20],[21].

\section{a. Quality of health services}

Quality of health services has great influence on utilization of health services and the study assessed this in terms of time taken within the health facility to receive treatment, how health workers handle patients, 
availability of other basic amenities and whether patients are given adequate time to explain their problems whenever they visit health facilities. Time taken within the health facilities to receive medical attention may influence health seeking behaviour of the people. Table 4 shows time taken between arrival to and departure from health facilities when patients visit health facilities to receive health services.

Table 4. Time taken within the health facility to receive treatment

\begin{tabular}{ccc}
\hline Time taken within health facility & Frequency & Percentage \\
\hline Less than 1 hour & 10 & $2.6 \%$ \\
$2-3$ hours & 64 & $16.7 \%$ \\
$3-4$ hours & 135 & $35.5 \%$ \\
$4-5$ hours & 126 & $32.8 \%$ \\
More than 5 hours & 49 & $12.8 \%$ \\
\hline
\end{tabular}

Regarding time taken between arrival and departure time within the health facility, almost $75 \%$ of health seekers spent more than 3 hours at the facility chosen to access medical services. Much as the study reveals thatmajority of the patients felt that they were handled in a good manner when they visited health facilities and that they were given adequate opportunity to explain their problems to the doctors in order to provide relevant diagnosis, the long waiting period before receiving services may be detrimental to those who need urgent attention and this may in the long run hinder utilization of such services.. These findings are important because, as revealed by Alderman and Lavy [22], as well as the findings of the study conducted in Nyeri, Kenya by Ngure [23], when patients perceive quality of health services as poor or low, their health seeking behavior reduces.

\section{b. Accessibility to healthcare services}

This study assessed accessibility to healthcare services in terms of distance to health facility, means of transport and availability of means of transport. Distance to health facilities determines people's ability to travel to such health facilities to seek medical attention. Table 5 shows average distance to health facilities according to the respondents interviewed.

Table 5. Average distance to health facilities

\begin{tabular}{ccc}
\hline Distance to health facilities & Frequency & Percentage \\
\hline Less than $1 \mathrm{~km}$ & 32 & $8.3 \%$ \\
$2-3 \mathrm{~km}$ & 137 & $35.7 \%$ \\
$5 \mathrm{~km}$ & 144 & $37.5 \%$ \\
$10 \mathrm{~km}$ & 60 & $15.6 \%$ \\
More than $10 \mathrm{~km}$ & 11 & $2.9 \%$ \\
\hline
\end{tabular}

As far as distance is concerned, some $58 \%$ of the respondents recorded that they had to travel more than $5 \mathrm{~km}$ to access health services, In fact, a whole $18 \%$ of the respondents had to do $10 \mathrm{~km}$ and over. Additionally, availability of reliable means of transport and the ability of people to afford such means determine their choice of which means of transport to use to reach health facilities. Table 6 shows means of transport to health facilities as revealed by the study.

Table 6. Means of transport to the nearest health facility

\begin{tabular}{ccc}
\hline Means of transport & Frequency & Percentage \\
\hline Walking & 128 & $33.3 \%$ \\
Bicycles/motor cycles & 155 & $40.4 \%$ \\
Public transport (vehicles) & 84 & $21.9 \%$ \\
Private vehicles & 17 & $4.4 \%$ \\
\hline Total & $\mathbf{3 8 4}$ & $\mathbf{1 0 0 \%}$ \\
\hline
\end{tabular}

The study reveals that 33.3\% walk to the health facilities, $40.4 \%$ use bicycles/motor cycles to reach health facilities, $21.9 \%$ use public vehicles while $4.4 \%$ use private vehicles to reach health facilities. This implies that $33 \%$ of those walking to health facilities most likely cannot afford to pay for the existing means of transport. It is also worth noting that very small proportion (4\%) of those interviewed used private vehicles. 
Accessibility issues for those living in rural areas are well documented, whether it is in developed countries [24], or developing countries [25]. This is not the only issue facing those in rural areas, where there may be questions about the quality of the service, capacity or the facilities of the nearest service. Perhaps there are few options for residents of these areas, and with limited choices, they are bound to use any health facility, whatever the quality instead of taking no action at all. Or perhaps instead they turn to alternative therapies [26], traditional methods [27] and/or self-medications [28],[29].

A number of factors influence the choice of a health service; namely, physical access to health care, including distance from the health facility; availability of transportation, and the condition of the roads. As established by Noorali and team [30], the distance separating potential patients from the nearest health facility is an important barrier to its use, particularly in rural areas. This was actually confirmed by this study and these factors individually and collectively influence utilization of health services in Homa Bay County especially in rural areas where there are no proper roads over long distances to health facilities coupled with lack of adequate means of transport to reach those facilities.

\section{c. Equity in healthcare provision}

The study assessed equity in healthcare provision in terms of responding to the health needs of the people especially the ability of health facilities to respond to common ailments in the county. Health needs were assessed in terms common ailments in Homa Bay County. Knowledge of common ailments informs the decision by health facilities to stock relevant drugs that can adequately address such common ailments in Homa Bay County. Table 7 shows common ailments in Homa Bay County as found out from the study.

Table 7. Common ailments

\begin{tabular}{ccc}
\hline Type of ailment & Frequency & Percentage \\
\hline Malaria & 114 & $29.7 \%$ \\
Respiratory Tract Infection & 113 & $29.4 \%$ \\
Diarrhoea & 42 & $10.9 \%$ \\
Pneumonia & 85 & $22.1 \%$ \\
Skin infection & 30 & $7.8 \%$ \\
\hline
\end{tabular}

As revealed in Table 3.7, the common ailments in the County are malaria, respiratory tract infection and pneumonia. Availability of relevant drugs is informed by knowledge of common ailments outlined above and this has influence on effective health response by the health facilities. Table 8 shows responses regarding availability of relevant drugs whenever patients visit health facilities.

Table 8. Availability of relevant drugs for common ailments

\begin{tabular}{ccc}
\hline Availability of all prescribed drugs & Frequency & Percentage \\
\hline All drugs & 171 & $44.5 \%$ \\
Not all drugs & 213 & $55.5 \%$ \\
\hline Total & $\mathbf{3 8 4}$ & $\mathbf{1 0 0} \%$ \\
\hline
\end{tabular}

Respondents were asked whether they get all the drugs whenever they visit health facilities and 44.5.5\% said that they received all drugs while 55.5\% mentioned that they don't get all drugs. This implies that majority of patients do not receive all prescribed drugs and hence may not be able benefit fully from the available health services. In some cases, not every patient can reach health facilities to access health services. Within this political and economic climate, diseases such as malaria and HIV\&AIDS have a large impact in Kenya and place a heavy disease burden on the State, the economy, on families and on social networks. Malaria accounts for more than a million deaths per year, 90 per cent occurring in sub-Saharan Africa and affecting children under five years of age. In Homa Bay County, 29.7\% of those interviewed mentioned that they had been to the health facility due to malaria and $29.4 \%$ had visited health facilities because of RTI, these being common ailments in the county, which is in line with the MoMS data of 2011 from the three districts. In order to address health needs of the people in Homa Bay County, health services should target the common ailments mentioned by the respondents. The study reveals that $45.5 \%$ of those interviewed received drugs when they visited health facilities and this implies that $54.5 \%$ don't get drugs. This means that a good proportion is not able to utilize health services when in need because the drugs are not adequate. 


\section{CONCLUSION}

Provision of adequate health services is important in addressing the health needs of the people in order to improve their quality of life. With increasing health demands, utilization of such services needs to be assessed critically. Although the government of Kenya and other stakeholders have made efforts to improve utilization of health services, there are a number of factors that negatively affect utilization as has been found out from the study.

While the government has allocated budget to health services at the district level in Homa Bay County, this budget is not sufficient and additional resources are to be raised from cost-sharing. With low income level of most people in Homa Bay County, raising money to pay for health services is a challenge and hence this affects utilization of health services in Homa Bay County. Further more, most of those who are not able to afford health services resort to other alternative medicine while others are influenced by cultural factors and hence do not seek medical attention at all.

Availability of health facilities is an important aspect of service delivery and $28 \%$ of those interviewed are still not able to reach health facilities. Additionally, staffing is inadequate in most of the health facilities in Homa Bay County. Other aspects that were assessed were availability of required drugs as well as supplies and equipment, and these were found to be inadequate. Inadequate staffing in most health facilities as well as shortage of drugs and other relevant supplies in these facilities hinder utilization of health services.

Quality of health services in Homa Bay County was assessed in terms of time taken within the health facilities, how health workers handle patients and availability of relevant drugs. From these findings, it can be concluded that quality of health services affect utilization of such services in Homa Bay County due to long time taken on the queue to receive treatment and how most health workers handle patients when they visit health facilities.

The study assessed accessibility to healthcare services in terms of distance to health facilities and means of transport to those health facilities as well as means of transport to reach the health facilities. The findings of the study reveal that most people travel long distances in order to receive health services and majority of them walk or use bicycles and motor cycles to reach those health facilities. These factors imply that they cannot fully benefit from the services provided by these health facilities.

Capacity to respond to the health needs of the people in Homa Bay County is a critical aspect of equity in healthcare provision. The study reveals that relevant drugs are not sufficient to treat common ailments in Homa Bay County. Additionally, most people interviewed felt that health facilities do not respond fully to the community's health needs in Homa Bay County.

From these findings, we suggest the following recommendations for improvement: government should improve budget allocation towards health care in order to cater for required health services and where there are deficits there should be plans for financial support from development and other implementing partners; the government should ensure adequate and trained health staff in the health facilities. In addition, these health facilities should be equipped with adequate drugs and other required supplies, including ambulances where necessary, in order to provide relevant health support as and when required; there is need to improve service delivery by adhering to the service charters that have been developed by most health facilities in Homa Bay County; and Ministry of Health should strengthen partnership with NGOs to improve in order to reach local communities who are unable to reach health facilities. Based on the findings of this study, an area being recommended for further research is the influence of culture on utilization of health services in Kenya.

\section{ACKNOWLEDGEMENTS}

Prof. Richard O. Muga, Chairman National Health Insurance Fund (NHIF) Board and Deputy Vice Chancellor, Great Lakes University of Kisumu (GLUK) gave us a lot of encouragement to determine the factors that influence utilization of health services in Homa Bay County as the findings would inform health systems strengthening in the county as well as provide evidence to inform national response in reversing trends in health sector. Dr. S. M. Magada of Ministry of Medical Services was very instrumental in providing authorization to conduct this research.

Utilization of health services has been a concern for various health stakeholders in Homa Bay County based on my discussions with Dr. Akeche, Dr. Oluoch and Dr. Omondi, the DMOHs for Rachuonyo, Homa Bay and Suba Districts respectively, and representatives from some health NGOs in Nyanza Province; Mildmay International, APHIAPlus, Plan International, AMREF, MSF and RTI. Their influence on the decision to research on the subject is gratefully acknowledged. Lastly but by no means the least, the lecturers as well as students were of great support to my studies and particularly this study. We wish to give them special thanks. 


\section{REFERENCES}

[1] Muga, et al., “The 2004 Kenya Service Provision Assessment (KSPA) 2004 Survey”, 2004.

[2] Ansari, et al., "Access of Health Care and Hospitalization for Ambulatory Care Sensitive Conditions", Medical Care Research Review, Victorian State Government, Department of Human Services, Australia, 2003.

[3] Celik, Y., Hotchkiss, DR., "The Socioeconomic determinants of maternal health care utilization in Turkey”, Social Science and Medicine, vol/issue: 50(12), pp. 1797-1806, 2000.

[4] Hunt, N., Marshall, K., “Exceptional Children and Youth”, Boston, M.A. Houghton Mifflin Company, 1994.

[5] Thisted, RA., "Are there Social determinants of health and disease?”, Perspectives in Biology and Medicine, vol/issue: 46(3), pp. 565-573, 2003.

[6] Naicker, S., "End-stage renal disease in sub-Saharan and South Africa”, Kidney International, vol/issue: 63(S83), pp. 119-122, 2003.

[7] Correa-Rotter, R. et al., "Early detection and prevention of diabetic nephropathy: a challenge calling for action for Mexico and the developing world”, Kidney International Supplement, 2004.

[8] Gwatkin, O.R., "Health inequalities and the health of the poor: What do we know? What can we do?", Bulletin of the World Health Organization, vol/issue: 78(1), pp. 3-18, 2000.

[9] Dustin, RT., "Health care utilization: Analyzing the Kenyan Health System”, 2010.

[10] Noorali, R., Luby, S., Rahbar, M., "Research report: Does use of a government service depend on distance from the health facility?”, Health Policy and Planning, vol/issue: 14(2), pp. 191-197, 1999.

[11] World Health Organization, "Declaration of Alma-Ata. In International Conference on Primary Healthcare", Editor, Alma-Ata, USSR, 1978.

[12] World Bank, "World development report 1993: Investing in health", Oxford: Oxford University Press, 1993.

[13] Hjortsberg, C., "Why do the sick not utilize health care? The case of Zambia”, Health Economics, vol/issue: 12(9), pp. 755-770, 2003.

[14] Onwujekwe, O., Ozuchukwu, B., "Is combination therapy for Malaria based on user-fees worthwhile and equitable to customers? Assessment of costs and willingness to pay in Southeast Nigeria”, Acta Tropica, vol. 91, pp. 101115, 2005.

[15] Glick, et al., "Education and Health Services in Madagascar: Utilization Patterns and Demand Determinants", Cornell University, Working Paper 107, 2000.

[16] Alderman, H., Lavy, V., "Household Response to Public Health Services: Cost and Quality Tradeofs”, World Bank Research Observer, vol/issue: 11(1), pp. 301, 1996.

[17] Ngure, et al., "Quality of health care services in Nyeri Districts, Kenya: Patients reception and their effects on service utilization”, 2007.

[18] Ha, N., Berman, P., Larsen, U., "Household utilization and expenditure on private and public health services in Vietnam”, Health Policy \& Planning, vol/issue: 17(1), pp. 61-70, 2002.

[19] Tuan, T., et al., "Comparative quality of private and public health services in rural Vietnam”, Health Policy and Planning, vol/issue: 20(5), pp. 319-327, 2005.

[20] Birungi, H. et al, “The policy on public-private mix in the Ugandan health sector: catching up with reality”, Health Policy \& Planning, vol/issue: 16(Suppl 2), pp. 80-87, 2001.

[21] Witter, S., Osiga, G., "Health service quality and users' perceptions in West Nile, Uganda”, International Journal of Health Planning \& Management, vol. 19, pp. 195-207, 2004.

[22] Rajeswari, R., et al., "Factors associated with patient and health system delays in the diagnosis of tuberculosis in South India”, International Journal of Tuberculosis \& Lung Disease, vol/issue: 6(9), pp. 789-795, 2002.

[23] Sudha, G., et al., "Factors influencing the care-seeking behaviour of chest symptomatics: a community-based study involving rural and urban population in Tamil Nadu, South India”, Tropical Medicine \& International Health, vol/issue: 8(4), pp. 336-341, 2003.

[24] Andrews, G., "Demographic and health issues in rural aging: a global perspective”, Journal of Rural Health (United States), vol/issue: 17(4), pp. 323-327, 2001.

[25] Mehrotra, S., Jarrett, SW., "Improving basic health service delivery in low income countries: 'voice' to the poor", Social Science \& Medicine, vol/issue: 54(11), pp. 1685-1690, 2002.

[26] Eisenberg, D., et al., "Trends in alternative medicine use in the United States, 1990-1997: results of a follow-up national survey”, Journal of the American Medical Association, vol/issue: 280(18), pp. 1569-1575, 1998.

[27] Good, C., Kimani, V., "Urban traditional medicine: A Nairobi case study”, East African Medical Journal, vol. 57, pp. 301-316, 1980.

[28] McCombie, SC., "Self-treatment for malaria: the evidence and methodological issues”, Health Policy \& Planning, vol/issue: 17(4), pp. 333-344, 2002.

[29] World Bank, “World development indicators”, Washington, DC: World Bank, 2006.

[30] Schulpen, T., Swinkels, W., "Machakos project studies. Agents affecting health of mother and child in a rural area of Kenya", XIX. The utilization of health services in a rural area of Kenya. Tropical Geography and Medicine, vol/issue: 32(4), pp. 340-349, 1980. 


\section{BIOGRAPHIES OF AUTHORS}

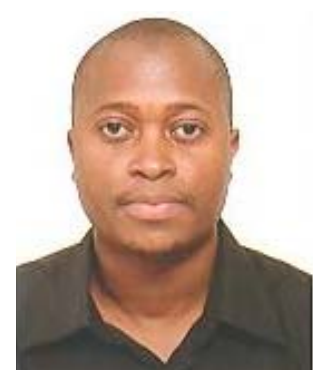

Otieno Stephen Odiwuor holds Bachelor of Science (B.Sc.) from Egerton University, Executive Master of Science from United States International University, Master of Arts in Project Planning and Management from the University of Nairobi, Advanced Health Management Programme from Foundation for Professional Development/Yale School of Public Health, and Master of Science in Development Management from the Open University - United Kingdom. Currently he is pursuing $\mathrm{PhD}$ in Development Studies at Jomo Kenyatta University of Agriculture and Technology. He has undergone various professional courses through which he has acquired key skills and knowledge in development issues. He has over 11 years' hands-on experience working with local and international NGOs focusing on Health and HIV \& AIDS; Livelihoods/IGAs and Food Security and Sovereignty; Environmental Management; Social Protection; Emergency and Humanitarian Response; Governance and Human Rights; Gender \& Women Empowerment and Peace-building \& Conflict Transformation. He has worked with AMREF International, Women in the Fishing Industry Programme (WIFIP) Education and Development, Mildmay International - Kenya, and HelpAge International - Africa Regional Development Centre. Currently he is working with Agency for Cooperation and Research in Development (ACORD) as Monitoring \& Evaluation and Knowledge Management Coordinator. He is a member of; Society of Educational Research and Education in Kenya (SEREK), The South Africa Institute of Health Care Managers (The SAIHCM), The International Society for Organization Development and Change (The ISODC), Evaluation Society of Kenya (ESK), and Africa Community of Practice on Managing for Development Results (CoP-MfDR-Africa).

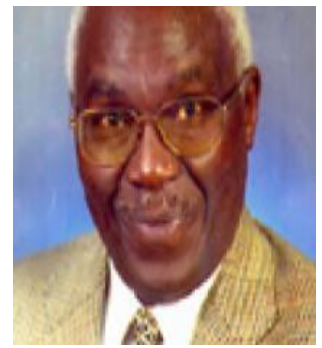

Prof. David Macharia is a Professor of Education at the University of Nairobi where he has been a staff member since 1965 and where he has risen through the ranks over time both academically and administratively. He holds a BA (Hons) in Geography and Economics from London University and MA in Instructional Communication frorm Syracuse University, New York. Apart from his teaching duties at various levels, he has supervised many Masters students and done lots of consultancy work. He has published widely in his areas of interest. He has served as Director of Adult Education in the Kenya Civil Service and has worked as Advisor in Adult Education to the governments of Somalia and Namibia as well as in South Africa where he offered leadership in staff training and development as well as in development of training materials in adult education and literacy and also in peace and conflict resolution. He has been Chief Facilitator for youth empowerment as well as Patron at Umtapo Cente, Durban, South Africa and also Patron of Peace Club at the University of Nairobi as well as being a member of Task Force for peace made up of students and staff members interested in propagation of peace in institutions of higher learning and in communities in Kenya. Prof. Macharia has been President of International Community Education Association, a Board member of International Councli of Adult Education, International Community-based Peace Builders (INTERCHANGE) and also of the World Peace Bureau. He has also received various honours including being the first recipient of the Steve Biko International Peace Award from the Umtapo Centre and also the Elder of Burning Spear (EBS) from the Kenya Government for exemplary service in education locally and elsewhere. 